This PDF is a selection from a published volume from the National Bureau of Economic Research

Volume Title: Risk Topography: Systemic Risk and Macro Modeling

Volume Author/Editor: Markus Brunnermeier and Arvind Krishnamurthy, editors

Volume Publisher: University of Chicago Press

Volume ISBN: 0-226-07773-X (cloth); 978-0-226-07773-4 (cloth); 978-0-226-09264-5 (elSBN)

Volume URL: http://www.nber.org/books/brun11-1

Conference Date: April 28, 2011

Publication Date: August 2014

Chapter Title: Liquidity Mismatch Measurement

Chapter Author(s): Markus Brunnermeier, Gary Gorton, Arvind Krishnamurthy

Chapter URL: http://www.nber.org/chapters/c12514

Chapter pages in book: (p. 99 - 112) 


\title{
Liquidity Mismatch Measurement
}

\author{
Markus Brunnermeier, Gary Gorton, \\ and Arvind Krishnamurthy
}

Policymakers and academics recognize that liquidity is central in the dynamics of a financial crisis, and that measurement of liquidity is critical in evaluating and regulating systemic risk. ${ }^{1}$ The proposed Basel liquidity coverage ratio, for example, calls for banks to maintain a sufficient buffer of liquid assets to cover outflows over the next thirty days.

Systemic risk depends primarily on the endogenous response of market participants to extreme events. Brunnermeier, Gorton, and Krishnamurthy's (2012) "Risk Topography" approach takes explicitly endogenous responses into account when collecting data on the value and liquidity factor exposure of major institutions. The liquidity measure is a key response indicator. Market participants react to the same shock very differently depending on whether they face a lack of liquidity or they are flush with liquidity. In addition, aggregate liquidity measures are important to detect a buildup of systemic risk in the background during a run-up phase.

The academic literature on liquidity has identified many different aspects

Markus Brunnermeier is the Edwards S. Sanford Professor of Economics at Princeton University and a research associate of the National Bureau of Economic Research. Gary Gorton is the Frederick Frank Class of 1954 Professor of Management and Finance at Yale School of Management and a research associate of the National Bureau of Economic Research. Arvind Krishnamurthy is the Harold L. Stuart Professor of Finance in the Kellogg School of Management at Northwestern University and a research associate of the National Bureau of Economic Research.

For acknowledgments, sources of research support, and disclosure of the authors' material financial relationships, if any, please see http://www.nber.org/chapters/c12514.ack.

1. Duffie (chapter 3, this volume) highlights liquidity risk, in addition to solvency and counterparty risk, in his 10-by-10-by-10 framework for assessing systemic risk. Acharya (chapter 6, this volume) and McDonald (chapter 5, this volume) evaluate approaches to measuring liquidity risk based on collateral/margins on derivative contracts. 
of liquidity that are important in crises, ranging from a bank's reliance on short-term debt, to its overall funding liquidity, to the market liquidity of its assets. The purpose of this chapter is to examine the measurement of liquidity in light of the academic research on liquidity. That is, the liquidity in a given academic paper is often a highly stylized concept. The questions we seek to answer are the following:

1. What is the practical and measured counterpart of the theoretical concept of liquidity suggested by models?

2. If one is interested in a liquidity measure that is informative about systemic risk, what measure does the academic research suggest?

Answers to these questions can inform regulatory thinking on liquidity regulations as well as further academic research in empirically testing models of liquidity and crises.

We propose a liquidity (risk) measure that looks at the worst $x$ percent of the stress scenarios. For each stress scenario and for each asset and liability a cash equivalent dollar value is assigned assuming that all counterparties withdraw as much funds as possible in this scenario.

\subsection{Liquidity in Theoretical Models}

Diamond and Dybvig (1983) is the canonical model emphasizing the importance of "funding liquidity" for understanding financial crises. In this model, it is not the borrowing or leverage of the financial sector that is salient, but rather the proportion of debt that is comprised of short-term demandable deposits. More broadly, the banking literature concludes that when the financial sector holds illiquid assets financed by short-term debt, the possibility of run behavior emerges and, in turn, can precipitate a crisis.

Brunnermeier and Pedersen (2009) model the interaction between an institution's ability to raise funds (funding liquidity) and the liquidity of the assets when it sells them (market liquidity). Here, when funding liquidity falls the institution provides less liquidity in the assets it trades, reducing the market liquidity of the assets. When these assets themselves serve as collateral for the loans taken on by the institution, the situation can precipitate an adverse feedback loop as decreased market liquidity tightens funding liquidity conditions, and vice versa. The literature also describes a feedback mechanism between capital problems and liquidity problems. See, for example, Allen and Gale (2004). When the financial sector runs into liquidity problems, triggered by runs by lenders, the sector sells assets whose prices then reflect an illiquidity discount. The lower asset prices lead to losses that deplete capital, further compromising liquidity. The critical point that emerges from this literature is that the liquidity of assets is endogenous, while in the Diamond and Dybvig analysis the market illiquidity of assets held by banks is taken to be fixed. This leads to the important conclusion, 
namely, that it can be misleading to measure the liquidity of assets during a quiescent period if one is interested in a liquidity measure that can be informative about financial crises. Importantly, it is the liquidity mismatch that matters, the market liquidity of the assets, that is, their price impact in times of crisis, relative to the maturity structure of the liabilities. Note the difference to the maturity mismatch concept. Holding thirty-year Treasury bonds financed overnight involves an extreme maturity mismatch, but the liquidity mismatch of such a position is limited as US Treasuries typically appreciate in times of crisis.

Gorton and Pennacchi (1990) point out that the function of the banking system is to issue (informationally insensitive) liquid short-term debt claims against illiquid assets. That is, functionally banks produce liquidity in much the same way that utilities produce electricity. Bank equity holders earn a liquidity premium on production of this liquidity. From this perspective, any accounting of financial sector liquidity should have the property that the sector has a negative aggregate amount of liquidity.

Holmström and Tirole (1998) and Caballero and Krishnamurthy (2004) offer a macroprudential analyses of aggregate liquidity. Both papers ask the question of whether the private sector will produce the socially efficient amount of aggregate liquidity, and both offer a negative answer. In an international context, Caballero and Krishnamurthy show that generally the private sector will go too far in liquidity production - issue too many shortterm debt claims - because individual actors do not internalize the effects of their actions on the probability of a macroeconomic crisis. Holmström and Tirole show that the state can play a beneficial role by itself issuing liquid claims, against its taxing power, in effect acting as a financial intermediary. Both of these analyses highlight the importance from a regulatory standpoint of measuring liquidity in a fashion that can be aggregated across the financial sector and hence shed light on macroeconomic risks.

To summarize, liquidity is constrained by financial frictions often in the form of limited pledgeability of future cash flows due to asymmetric information. The theoretical literature offers the following lessons regarding liquidity:

1. It is important to measure the liquidity of a given economic unit using data both on the market liquidity of its assets and on the liquidity promised through its liabilities. The measures need to explicitly condition on a possible stress event.

2. Liquidity is also a "response indicator." It reveals firms' or a sector's reaction to shocks and whether they potentially lead to adverse feedback loops in the form of liquidity spirals. A situation where the financial sector has promised more liquidity than it has is what we should expect as the natural state of the financial sector. On the other hand, this natural state gives rise to the possibility of financial crises. 
3. Measuring the aggregated liquidity of the financial sector can be informative for macroprudential policy.

\subsection{Liquidity in Practice}

We next turn to the practical issues in liquidity measurement. In practice, liquidity does not match up neatly with representations of stylized models. We illustrate the issues through a series of examples.

Liquidity mismatch. Consider a bank with $\$ 20$ of equity and $\$ 80$ of debt, where half the debt is overnight repo financing at 1 percent and the other half is five-year debt at 4.5 percent. The bank buys one agency mortgagebacked security (MBS) for $\$ 50$ (which is financed via repo at a zero haircut) and loans $\$ 50$ to a firm for one year at an interest rate of 5 percent.

What if the bank cannot renew the repo financing, and is forced to liquidate some of its assets? Standard measures, such as leverage, will not capture this liquidity risk. That is, they will treat the overnight debt and the five-year debt symmetrically. One could construct a leverage measure that focuses on the maturity mismatch in this example - for instance, a short-term leverage measure - but this too may prove inadequate. For example, suppose that instead of the agency MBS, the bank owned \$50 of private-label MBS, which is less liquid than the agency MBS. Now this bank has more of a liquidity mismatch, stemming from the asset side. Thus, it is clear that a liquidity measure needs to incorporate information from both the asset side of the balance sheet and the liability side, that is, both market liquidity and funding liquidity.

Rehypothecation. The bank lends $\$ 100$ to a hedge fund for one day and receives a bond with a market value of $\$ 100$ as collateral (a reverse repo). The bank then uses the bond as collateral to borrow $\$ 100$ in the overnight repo market. (Whatever else the bank is doing we ignore for purposes of the example.)

This bank, despite having a liability structure comprising of short-term debt, does not have liquidity risk. Suppose that the repo lender to the bank does not renew this repo. Then, the bank can also choose not to renew its repo loan to the hedge fund and thus unwind the debt position. Again, this example illustrates that it is important to use information from the asset side to measure liquidity. Note instead that if the reverse repo loan to the hedge fund is for three days, then the bank will have some liquidity mismatch.

Derivatives. Consider a firm with $\$ 20$ of equity and $\$ 80$ of debt; half the debt is overnight repo financing at 1 percent and the other half is fiveyear debt at 4.5 percent. The firm buys $\$ 100$ of US Treasury securities and writes protection (using credit default swaps [CDS]) on a diversified portfolio of 100 investment-grade US corporates, each with a notional 
amount of $\$ 10$, so there is a total notional of $\$ 1,000$. The weightedaverage premium received on the CDS is 5 percent.

Derivatives trade under the International Swaps and Derivatives Association master agreement. This agreement usually has a credit support annex (CSA), a legal document, which sets forth the conditions under which each party must post collateral. Suppose that in this example the CSA has collateral-posting requirements based on the market value of the CDS position. If the marks widen, that is, when it is more likely that a firm or firms in the portfolio will default, this firm will have to post collateral to the counterparty. It has a Treasury bond, which could be posted, but which would then reduce the amount of asset liquidity held by the firm. In the extreme, imagine that the entire Treasury holding is posted so that the firm no longer has any liquidity. Then, the only remaining asset the firm has is the CDS portfolio.

As another example of a liquidity event triggered by derivatives, consider the effect of a ratings downgrade. The CSA often prescribes that if the bank is downgraded during the term of the derivative contract, it will have to post more collateral, which again uses liquidity. Moreover, if the firm had written many derivative contracts - the CDS as in the example, plus interest rate derivatives - the need for liquidity will apply to all derivative contracts. Thus, the downgrade is potentially a significant liquidity risk that arises when firms use derivatives.

Credit lines. The bank has $\$ 20$ of equity and $\$ 80$ of five-year debt. The bank buys $\$ 100$ of US Treasuries and offers a credit line to a firm to access up to $\$ 100$.

In this example, as with the derivatives example, the bank has no illiquidity problem currently. However in the event that a firm draws down the credit line, the $\$ 100$ of Treasuries will convert into a less liquid bank loan. Thus, this bank has acquired liquidity risk.

Forwards versus futures. A (Brazilian) sugar producing firm writes a forward contract to deliver $\mathrm{X}$ amount of sugar after the harvest. Alternatively, the firm could have also bought a large futures contract on the exchange that is marked to market on a daily basis.

In this example, the firm is naturally hedged against sugar price fluctuations, as it is a major sugar producer. Locking in the price via a forward creates no liquidity risk or fundamental risk for the firm. However, if the firm opts for an exchange-traded futures contract instead, it is subject to margin calls as the sugar price varies. Hence, the firm has to hold large cash reserves for this case.

Currency mismatch. A European bank has (euro) \$2 equivalent of equity, $\$ 40$ equivalent of euro retail deposit funding, and \$40 of US overnight commercial paper. The bank owns $\$ 100$ of ABS. 
In this example, the bank is running a currency mismatch, owning dollar assets funded by retail euro deposits as well as dollar wholesale funding. Suppose that money market funds refuse to roll over the commercial paper. In this case, the bank will not be able to keep its ABS position.

Note that the real issue here is the maturity of the dollar debt and not the currency mismatch. That is, if the firm had long-term dollar debt, the firm would have no liquidity risk.

\subsection{The Liquidity Mismatch Index (LMI)}

We next present a theoretical liquidity measure, informed by the academic literature on liquidity, and analyze its benefits in terms of assessing liquidity risk both from a firm and macroprudential perspective.

There are two dates. Date 0 is the ex ante date at which each firm makes risk and liquidity decisions by choosing cash assets and cash liabilities, as well as derivative positions and off-balance sheet positions. Derivative positions may have a market value of 0 at date 0 , but are sensitive to the risk factors. At date 1 a state $\omega \in \Omega$ is realized, one of which may be a systemic crisis, depending on what decisions firms have made. We will define a liquidity index for each state as well as a summary liquidity index for date 0 .

Firm $i$ chooses assets $A^{i}$ and liabilities $L^{i}$. The assets are a mix of cash, repo lending to other firms, derivative exposure, outright asset purchases, and so forth. Liabilities include short-term debt, long-term debt, secured debt, equity, and others. We also consider hybrid contracts such as credit lines extended, which alter the firm's assets when they are drawn down.

\subsubsection{Liquidity Risk Exposure and Cash Liquidity}

We determine "liquidity risk exposure" at date 0 in two steps: First, we derive for each state at date 1 the cash-equivalent value of each asset and liability. Second, the liquidity risk measure at date 0 focuses on the, say, 5 percent worst draws of nature. In this sense our $t=0$ liquidity risk measure follows the same method as standard risk measures like value at risk (VaR) or expected shortfall.

Cash liquidity for a given stress scenario. More specifically, the cash equivalent value in a specific state $\omega \in \Omega$ after nature has moved to realize a particular stress event for the firm is the value of the firm assuming that:

- Counterparties act most adversely. That is, parties that have contracts with the firm act to extract as much cash as possible from the firm under the terms of their contracts. This defines the liquidity liability.

- The firm computes its best course of action, given the assumed stress event, to raise as much cash against its balance sheet as it can to withstand the cash withdrawals. That is, the firm computes how much cash it can raise from asset sales, preexisting contracts such as credit lines, 
and collateralized loans such as repos backed by assets currently held by the firm. The computation assumes that the firm is unable to raise unsecured debt or equity (following, see how to account for access to equity markets at some time in the future). The total cash raised is the liquidity asset.

The net of the liquidity asset and the liquidity liability is the LMI for that state. For each "relevant" state $\omega \in \Omega$ or stress scenario the LMI is calculated. Examples of stress scenarios are: the firm is downgraded, the haircuts on the firm's assets rise, the market for securitized assets turn illiquid, all credit spreads rise, and so forth.

Liquidity risk. The date 0 liquidity risk measure focuses on the worst stress scenarios. If one uses expected shortfall liquidity risk measure then one considers the $x$, say 5 percent, worst scenarios. Each of the worst scenarios gets the same weight. The value-at-liquidity risk is determined by the scenario that is closest to the $x$ percent worst scenario.

In short, we assume that in each state $\omega \in \Omega$ counterparties take the worst action and the firm finds the best response (defense action) after nature's choice of $\omega$. With regard to the choice of nature we focus on the worst $x$ percent.

Our liquidity measure captures well the liquidity risk of all positions, including derivatives positions. Indeed, our measure is related to the margin dollar amount that McDonald (chapter 5, this volume) and Acharya (chapter 6 , this volume) propose. In this sense our liquidity measure provides a unified approach across various asset classes and liabilities.

One attractive feature of our measure is that it can be expressed in terms of dollars like standard risk measures. This has the advantage that it can be aggregated across various institutions in a meaningful way. Note practitioners often use the maximum time an institution can survive without raising new funds in an environment in which counterparties and nature move against them. While this measure is useful for a single institution, it cannot be easily aggregated across institutions.

Before delving into the LMI analysis we provide (a) some examples, (b) details about how cash equivalent liquidity $\lambda$-weights are chosen, (c) some guidance as to how relevant stress scenarios $\omega$ are picked, and (d) steps on how the date 0 liquidity risk measure is determined.

Here are some examples to ground this definition:

1. If a firm has $\$ 100$ of risk-free overnight debt, then the cash equivalent of this debt is $\$ 100$ because the debtor can extract $\$ 100$ by refusing to roll over the debt. Note that this $\$ 100$ liquidity liability applies in all states, because the $\$ 100$ from overnight debt can be extracted in all states of the world.

2. If a firm has a CSA that allows counterparties to extract more cash collateral if the firm is downgraded, then only in the downgrade state is there 
a liquidity liability for the firm (equal to the maximum amount of collateral posted, as stipulated by the contract).

3. If a firm has $\$ 100$ of Treasury securities, then the cash-equivalent value of these securities is $\$ 100$ because we assume that Treasuries are always liquid.

4. If a firm has $\$ 100$ of MBS with a repo haircut in a good state of 5 percent and a repo haircut in a bad state of 15 percent, then the cash-equivalent value in the good state is $\$ 95$, while it is $\$ 85$ in the bad state.

5. If a bank has written a $\$ 100$ credit line to another firm that is uncontingent, then the "worst-case" computation means that the credit line is fully drawn down, resulting in a $\$ 100$ liquidity liability. Now, the best response for the firm may be to take the resulting loan and raise cash against it (in the simplest case with cash from the same bank, or in more complicated cases through loan sales). Suppose that the firm raises $\$ 80$ of cash against the loan, then the $\$ 80$ of cash raised is offset against the $\$ 100$ credit line drawn to give a liquidity mismatch of $-\$ 20$.

Liquidity weights. The way we implement the LMI is to assign a liquidity weight $\lambda_{\omega}^{j}$ to each asset and liability for each state of the world. Assets are indexed with positive $j$, while liability $j$ takes on a negative value. We normalize super-liquid monetary assets such as bank reserves and Treasuries to have $\mathrm{a} \lambda_{\omega}^{\text {money }}$ of one across all states. For something like a mortgage-backed security (MBS), we can imagine measuring $\lambda_{\omega}^{M B S}$ as one minus the repo haircut on that MBS in state $\omega$. Alternatively, $\lambda_{\omega}^{M B S}$ could measure the price discount that firm $i$ has to accept if it immediately wanted to convert the asset into cash. The weights $\lambda_{\omega}^{j}$ measure the cash-equivalent value of asset $j$, as just described as the answer to the question, what is the maximum amount of cash that can be raised against a given asset? Aggregating liquidity across the asset side, one obtains firm $i$ 's asset liquidity $\Lambda_{\omega}^{A, i}$ for the different states of the economy. We also measure the liquidity of the liabilities as $\lambda_{\omega}^{j}<0$. Overnight debt has liquidity of -1 in all states. A derivatives contract has a weight $-1<\lambda_{\omega}^{D E R}<0$, in the state where the firm is downgraded or loses money on the derivative. The weight here reflects the maximum collateral posted in that state. If the margins/haircuts of a collateralized position can be increased from say 10 percent to 50 percent at the discretion of the financier, then essentially 40 percent of the position is financed by overnight debt. A credit line that is uncontingent has a weight that is the net between the liquidity lost when the line is drawn (weight $=-1$ ) and the asset liquidity from the loan made (weight $>0$ ). This net number will be negative so that we consider it a liquidity liability. Common equity is $\lambda_{\omega}^{\text {equity }}=0$ for all states $\omega$. The same applies to long-term debt. Overall, firm $i$ 's liquidity position is $\Lambda_{\omega}^{i} \equiv \Lambda_{\omega}^{A, i}-\Lambda_{\omega}^{L, i}$, which we note is a function of the state $\omega$.

An important consideration that arises with the liquidity weights is how to account for government insurance. For example, is it appropriate to include 
liquidity that can be obtained from the discount window? How should one handle the fact that government insurance of retail deposits makes such deposits far less run prone? We are interested in a measure of liquidity that can indicate when a systemic crisis is more likely. Since a crisis is an equilibrium outcome of an economy with government insurance, it is appropriate to take measurements that include government insurance. Thus, the best response of a firm accounts for the possibility of borrowing from the discount window. One can imagine a stress scenario in which discount window haircuts doubled, were subject to increased stigma, and so forth. However, the appropriate calculation for the LMI should still assume the existence of the discount window. Second, we assume that retail deposits pose no liability liquidity risk. This latter assumption comes from a great deal of evidence that in a macrostress event, the banking sector receives deposits in a flight to safety (see Gatev and Strahan 2006). Note that pure microliquidity risk considerations may lead one to consider that retail deposits are a liquidity liability, but that is an inappropriate perspective from a systemic risk standpoint.

One further conceptual issue in this computation is the time dimension. The LMI can only be defined for some time period. An overnight LMI is a computation that assumes only overnight contracts are not rolled over, and that after that the firm is able to raise equity. A thirty-day LMI is a computation that assumes that all debt maturing in the next thirty days is not rolled over, and that after the thirty days, the firm is able to raise equity to cover further obligations. How should time be handled and what is the relevant time frame for the liquidity measurement? We try to incorporate the time dimension by adjusting the $\lambda$-liquidity weights.

For the first question, we proceed as follows. Suppose that having free access to liquidity (e.g., being able to access equity markets) follows a Poisson process. There is a probability $\theta$ that the firm is able to raise equity in any given day (in principle $\theta$ can be a different number tomorrow, the day after that, etc.). Then, the LMI is based on the expected liquidity outflow going forward. Define the function $f(t, \theta) \in[0,1]$, where $t=1$ corresponds to "one day" and $t=30$ is thirty days, as the probability that the firm is unable to access free liquidity by date $t$. The probability is decreasing in $t$ at a decay rate governed by the parameter $\theta$. All liability contracts with payments due at date $t$ have $\lambda_{\omega}^{j, t}$ equal to $f(t, \theta)$ times the $\lambda_{\omega}^{j}$ for the same contract if its payments were due at date $t=1$. Thus, thirty-day debt has $\lambda_{\omega}^{j, 30}=-1 \times f(30, \theta)$. This discounting structure has the property that standing at any date $t>0$ where the firm is still liquidity constrained, the liquidity of a given contract is the same as at date 0 .

The next question is how should one choose $\theta$ ? We turn back to the academic literature. Models such as Diamond and Dybvig (1983) and Gorton and Pennacchi (1990) identify that the financial sector creates liquidity by issuing short-term debt claims. We would like measures to be informative 
of how much of this liquidity production is being done by the financial sector. The theoretical models imply that the relevant short-term debt carries a liquidity premium. Thus to map the models to practice, we need to identify what maturities of short-term debt carry a sizable liquidity premium. Greenwood, Hanson, and Stein (2010) document that Treasury bills with less than three months to maturity carry a liquidity premium. On average, over a sample from 1990 to 2006, the premium on the one-week bill relative to the six-month bill is 32 basis points. The premium is a nonlinear function of time, rising quickly and hitting about 5 basis points for the threemonth bill.

Thus, consider fitting the function $f(t, \theta)$ to the liquidity premium evidence from the Treasury bill market, so that the function is near zero by $t=90$. Note that the parameter $\theta$ can be part of the stress event (i.e., the state $\omega$ ), so that, in systemic risk states where market measures of liquidity premia at all maturities rise, the measure naturally extends to incorporate more time into the construction of liquidity liabilities. However, the baseline can reflect the average liquidity premium evidence as captured in the Treasury bill market.

The determination of the liquidity weights is also primarily an empirical question. There is a large empirical finance literature on liquidity that can provide some guidance to setting the liquidity weights. For example, this approach will be closest to Krishnamurthy and Vissing-Jorgensen (2010) who measure the liquidity convenience of assets based on bond market spreads. For some security markets, another alternative would be to use repo haircuts. For other assets, bid-ask spreads, price impact measures, or trading volume can be used as guides for the liquidity weights.

However the base case is determined, different liquidity scenarios correspond to different specifications of weights, shocking one or more at a time. Here again, the empirical finance literature can be used to guide the exercise. There is a large literature that documents the time-series variation in liquidity measures such as bond-market spreads and stock market liquidity, as well as the covariances of these measures with aggregate risk factors. These patterns can guide the choice of liquidity scenarios. Consider an $\omega$ macro state described by movements in some underlying factors. From historical empirical work, we know the covariance between the factors and the aggregate liquidity measures. Thus, we can consider percentage deviations from the base-case set of liquidity weights based on moves in the aggregate liquidity measures.

Scenarios. The dimensions of the $\Omega$ state space that describes a firm's asset, liability, and liquidity positions can be huge. For practical reasons, suppose that liquidity measurements only focus on states $s$ within an $S$-dimensional factor space, a subspace of $\Omega$. Factors consist of certain prices (risk factors) or liquidity/funding conditions (liquidity factors).

Some examples of a liquidity risk scenario are the following: 
- Firms are unable to access the market to raise new cash for one month, three months, and six months.

- Repo haircuts on some asset classes rise.

- The syndicated loan market, or the securitization market, shuts down for some period.

Once again, these are just examples, and the actual scenarios will depend on prevailing economic conditions.

Date 0 liquidity. The previous computations describe $\Lambda_{\omega}^{i}$, that is, in a particular stress event. In practice, it is infeasible to compute a complete statecontingent vector $\Lambda_{\omega}^{i}$. We are also interested in computing a single LMI at date 0 to summarize the liquidity position of the firm.

The following example illustrates our main consideration in defining the date 0 measure. Consider a highly rated firm that engages in an OTC interest rate swap contract that currently requires no collateral to be posted. From a liquidity standpoint, there will be states at date 1 where the firm will lose liquidity, but the firm at date 0 does not lose liquidity. Now consider an exchange-traded futures contract with the same risk profile as the swap contract. In this case, the firm posts collateral at date 0 , which results in a loss of liquidity. We describe a measure that ensures that the possibility of the liquidity loss at date 1 in the derivatives case leads to a liquidity liability at date 0 commensurate to the margin posted on the futures contract. This example is similar to the forwards versus futures example we discussed earlier.

We measure the expected liquidity loss in the $x$ percent (e.g., 5 percent) worst case for the derivatives contract. This computation is analogous to the expected shortfall measure common in risk management. Then the liquidity liability at date 0 for the derivative contract is this expected liquidity loss. For each state and asset/liability, we compute this expected liquidity loss. The overall LMI weighs all of these scenarios.

This appears complicated because it requires one to compute each LMI for each scenario. However, note that the LMI computation is linear so that it is equivalent to computing the expected shortfall for each stress separately and then simply aggregating across the stress events.

We denote the liquidity position at date 0 as $\Lambda_{0}^{i}$ For each $\omega$, we can define $\Delta \Lambda_{\omega}^{i} \equiv \Lambda_{\omega}^{i}-\Lambda_{0}^{i}$ as the change in liquidity for that firm due to that particular state or scenario.

\subsection{Analyzing the LMI}

The LMI measure incorporates the ideas from the academic literature on liquidity. First, it explicitly accounts for asset and liability liquidity, as many papers have emphasized. Second, since liquidity is measured conditional on 
a given $\omega$ macro state, the LMI explicitly accounts for liquidity risk - that is, the possibility that asset and liability liquidity are state dependent. Finally, as we discuss next, the LMI can be aggregated across firms and sectors. This is important for a macroprudential assessment of systemic risk.

Liquidity aggregates. An interbank loan that is a liquid asset for firm $i$ is a drain on liquidity for the borrower, firm $j$ (i.e., negative liquidity weight). Aggregating across firm $i$ and firm $j$, the interbank loan will net out. Consider the net liquidity index for firm $i$,

$$
\Lambda^{i}=\Lambda^{A, i}-\Lambda^{L, i} .
$$

Again consider the sum,

$$
\sum_{i}^{I} \Lambda^{i} .
$$

Summed across all sectors, the liquidity aggregate equals the supply of liquid assets: the $\lambda$-weighted sum across all relevant liquid assets. The aggregate measures are analogous to Barnett's (1980) Divisia indices for monetary aggregates. Barnett devised indices to weight different components of the money supply based on their usefulness as a transaction medium. The LMI index is similar but is based on both assets and liabilities, and has weights that reflect the financial liquidity of the asset and liability.

The aggregates are most interesting in describing the liquidity position of particular sectors. We may expect to find, for example, that the banking sector always carries a negative liquidity position, as suggested by Gorton and Pennacchi (1990), while the corporate sector or household sector carries a long liquidity position. The extent of liquidity transformation done by the banking sector may also be informative for diagnosing systemic risk. For example, in the period from 2000 to 2008 , it is likely that the aggregate LMI grew substantially. However, for systemic risk purposes, what would have been most interesting is a diagnosis that the aggregate growth reflected an increasing mismatch between the banking sector and the other sectors in the economy.

Intermediation chains. Note that the aggregation of liquidity given a specific stress scenario $\omega$ only punishes long intermediation chains to the extent that $\lambda$-weights of the market liquidity of assets differ from the liability $\lambda$-weights. If the weights are symmetric, that is, in the case in which the weight of a loan from firm $i$ (asset for that firm) is equal to the negative of the weight of that loan to firm $j$ (liability for that firm), then aggregation over an intermediation chain is neutral. However, for asymmetric weights intermediation chains lead to a higher liquidity mismatch.

For the date 0 liquidity (risk) measure, total liquidity in the economy shrinks as the intermediation chain lengthens. To see this, consider the stylized case in which two financial institutions only write one derivatives contract on a specific asset. The worst $x$ percent $\omega$-scenarios for one institution are the states in which the underlying asset moves in one direction, while for 
the other institution the opposite scenarios are the bad scenarios. In other words, both institutions focus on different worst scenarios (and ignore their favorable scenarios). This reduces the aggregated liquidity measure as long as the derivative contract does not hedge other risks. More generally, longer intermediation chains significantly reduce our liquidity measure. This is a desirable property, as it is widely thought that financial fragility is created by the long chains of assets and liabilities that underlie the securitization model (i.e., household mortgage, packaged into MBS, further packaged into CDO, and then serving as collateral for a repo, which may be rehypothecated many times). The aggregate LMI can measure this fragility.

Systemically important institutions. New banking regulations require greater oversight and higher capital requirements for systemically important institutions. One cut at judging who is systemically important is to rank institutions by size of assets. However, this type of ranking suffers from the same shortcomings as relying on balance sheet entries for asset holdings, which we discussed earlier. Economically, it is more meaningful to judge firms in terms of their magnitude of their risk exposures and liquidity exposures. Thus, the LMI index at the firm level can provide guidance on which institutions should be judged systemically important.

\subsection{Conclusion}

We have described and analyzed the benefits of the LMI, a liquidity metric. Since liquidity plays a central role in systemic crises, the LMI can be informative about systemic risks. Of course, the proof of the pudding will be in its empirical implementation. Early work in this regard appears promising (see Bai, Krishnamurthy, and Weymuller 2013). To close our theoretical discussion, we describe an important challenge in the use of the LMI to analyze systemic risk.

In practice, the liquidity weights $\lambda_{\omega}^{j}$ are endogenous to the state. For the purpose of measuring the risks for a firm, it is appropriate to take the $\lambda_{\omega}^{j}$ as exogenous; in a similar manner, it is appropriate to take market prices as exogenous when measuring the capital of a bank. However, for macroprudential purposes it is important to understand how $\lambda_{\omega}^{j}$ depends on the state. From a conceptual standpoint, we think of the $\lambda_{\omega}^{j}$ as akin to "market prices." The behavior of agents in the economy plus market clearing conditions describes the liquidity weights. For example, if the liquidity of assets is dependent on the financial health of a key set of financial intermediaries, then data on how the capital/liquidity of these financial intermediaries depends on the event $\omega$ can be useful in endogenizing the liquidity weights. From this standpoint, the LMI data needs to be fed into an economic model that endogenizes liquidity in order to fully describe systemic risk. We discuss the connection between measurement and modeling in Brunnermeier, Gorton, and Krishnamurthy (2012). 


\section{References}

Allen, Franklin, and Douglas Gale. 2004. "Financial Intermediaries and Markets." Econometrica 72:1023-61.

Bai, Jennie, Arvind Krishnamurthy, and Charles-Henri Weymuller. 2013. "Measuring Liquidity Mismatch in the Banking Sector." Working Paper, Northwestern University.

Barnett, William A. 1980. "Economic Monetary Aggregates: An Application of Aggregation and Index Number Theory." Journal of Econometrics 14:11-48.

Brunnermeier, Markus, Gary Gorton, and Arvind Krishnamurthy. 2012 "Risk Topography." In NBER Macroeconomics Annual 2011, edited by Daron Acemoglu and Michael Woodford. Chicago: University of Chicago Press.

Brunnermeier, Markus, and Lasse Pedersen. 2009. "Market Liquidity and Funding Liquidity." Review of Financial Studies 22 (60): 2201-38.

Caballero, Ricardo, and Arvind Krishnamurthy. 2004. "Smoothing Sudden Stops." Journal of Economic Theory 119:104-27.

Diamond, Douglas, and Phillip Dybvig. 1983. "Bank Runs, Deposit Insurance, and Liquidity." Journal of Political Economy 91:401-19.

Gatev, Evan, and Philip Strahan. 2006. "Banks' Advantage in Hedging Liquidity Risk: Theory and Evidence from the Commercial Paper Market." Journal of Finance 61 (2): 867-92.

Gorton, Gary, and George Pennacchi. 1990. "Financial Intermediaries and Liquidity Creation." Journal of Finance 45 (1): 49-71.

Greenwood, Robin, Sam Hanson, and Jeremy Stein. 2010. "A Comparative Advantage Approach to Government Debt Maturity.” Working Paper, Harvard University.

Holmström, Bengt, and Jean Tirole. 1998. "Private and Public Supply of Liquidity." Journal of Political Economy 106 (1): 1-40.

Krishnamurthy, Arvind, and Annette Vissing-Jorgensen. 2010. "The Aggregate Demand for Treasury Debt.” Working Paper, Northwestern University. 